\title{
Title:
}

\section{Unexpected diagnosis for nodular hepatic lesions}

\section{Authors:}

Isabel Garrido, Rosa Coelho, Joanne Lopes, Guilherme Macedo

DOI: $10.17235 /$ reed.2021.8230/2021

Link: PubMed (Epub ahead of print)

Please cite this article as:

Garrido Isabel , Coelho Rosa, Lopes Joanne, Macedo Guilherme. Unexpected diagnosis for nodular hepatic lesions. Rev Esp Enferm Dig 2021. doi: 10.17235/reed.2021.8230/2021.

This is a PDF file of an unedited manuscript that has been accepted for publication. As a service to our customers we are providing this early version of the manuscript. The manuscript will undergo copyediting, typesetting, and review of the resulting proof before it is published in its final form. Please note that during the production process errors may be discovered which could affect the content, and all legal disclaimers that apply to the journal pertain. 
CC 8230

\section{Unexpected diagnosis for nodular hepatic lesions}

Isabel Garrido ${ }^{1,2}$, Rosa Coelho ${ }^{1,2}$, Joanne Lopes ${ }^{3}$, and Guilherme Macedo ${ }^{1,2}$

${ }^{1}$ Gastroenterology and Hepatology Department and ${ }^{3}$ Pathology Department. Centro Hospitalar Universitário de São João; ${ }^{2}$ World Gastroenterology Organization (WGO) Porto Training Center

Correspondence: Isabel Garrido

e-mail: isabelmng@hotmail.com

Author contributions: Isabel Garrido drafted the manuscript. Isabel Garrido, Rosa Coelho, Joanne Lopes, and Guilherme Macedo have critically revised and finalized the manuscript. All authors have approved the final version of the manuscript.

Statement of ethics: all the rules established by the local ethics committee were followed, preserving patient identity and confidentiality.

Conflicts of interest statement: the authors have no disclosures to report.

Financial support: none.

Keywords: Uveal melanoma. Liver metastases. Liver biopsy.

Dear Editor,

Uveal melanoma is the most common primary ocular tumor and has a significant predilection for metastasis to the liver (1). Nevertheless, metastatic uveal melanoma usually occurs in the first years after the initial treatment, and late recurrence is 
extremely rare (2).

We report the case of an 83-year-old female who was diagnosed with right uveal melanoma in 2009. She underwent external beam radiation therapy and has been under surveillance since then. In 2021, the patient was observed in the Emergency Department after a fall resulting in chest trauma. A computed tomography scan of the chest was performed as she complained of pain. Besides multiple rib fractures, a nodule of $28 \mathrm{~mm}$ was identified in the right lobe of the liver (Fig. 1A) and liver tests were normal. The patient underwent abdominal magnetic resonance imaging to better clarify the etiology of the liver injury, which revealed a liver with normal dimensions, regular contours, and a homogeneous structure. However, there were more than 15 nodular lesions in the hepatic parenchyma (Fig. 1B). An echo-guided biopsy of the largest nodule was performed and a histological examination revealed liver metastasis of intraocular melanoma (Fig. 1C-D). An eye examination was subsequently performed, with no evidence of local recurrence. The patient started treatment with palliative chemotherapy due to her advanced age, multiple comorbidities, and diffuse metastatic lesions.

We present a rare case of liver metastases from an uveal melanoma that relapsed 12 years after initial diagnosis and curative-intent treatment. Metastatic uveal melanoma is a very challenging lesion to treat because surgical resection is rarely possible and there is no standard effective systemic therapy (3). The prognosis of these patients is extremely poor and directly related to the progression of the disease to the liver (4). Therefore, the introduction of universal surveillance protocols to identify metastatic disease at an early stage should be considered.

\section{REFERENCES}

1. Abramson DH, Schefler AC, Dunkel IJ, et al. Neoplasms of the eye. In: Bast R Jr, Kufe D, Pollick R, editors. Cancer medicine. 7th ed. London: BC Decker; 2006. pp. 1071-83.

2. Aguirre-Ghiso JA. Models, mechanisms and clinical evidence for cancer dormancy. Nat Rev Cancer 2007;7(11):834-46. DOI: 10.1038/nrc2256 
3. Callejo SA, Antecka E, Blanco PL, et al. Identification of circulating malignant cells and its correlation with prognostic factors and treatment in uveal melanoma. A prospective longitudinal study. Eye (Lond) 2007;21(6):752-9. DOI: $10.1038 /$ sj.eye.6702322

4. Rowcroft A, Loveday BPT, Thomson BNJ, et al. Systematic review of liver directed therapy for uveal melanoma hepatic metastases. HPB (Oxford) 2020;22(4):497-505. DOI: 10.1016/j.hpb.2019.11.002
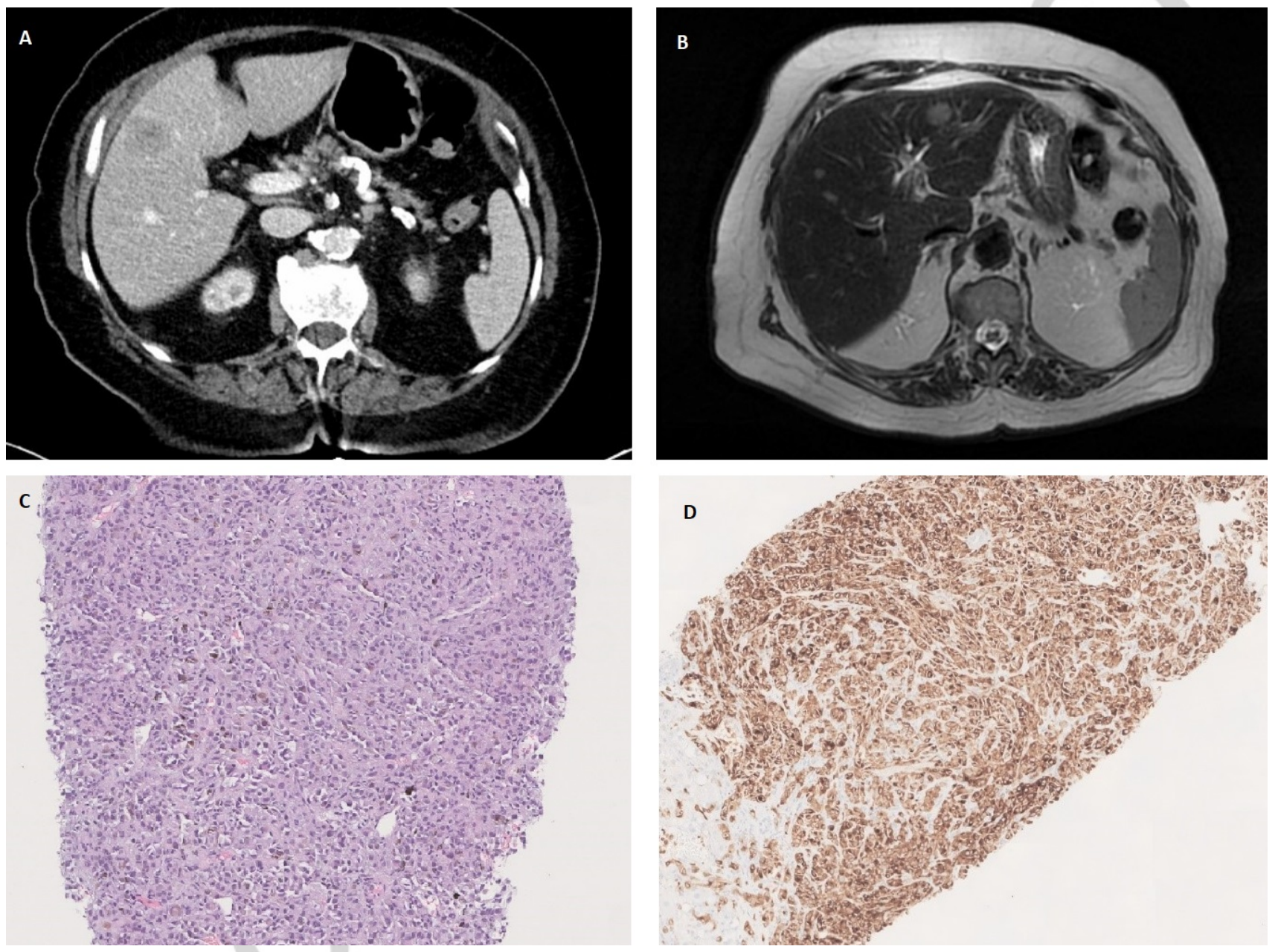

Fig. 1. A) Computed tomography showed a hypodense nodule of $28 \mathrm{~mm}$ located in segment $\mathrm{V}$ of the liver. B) Magnetic resonance imaging revealed several nodular lesions in the hepatic parenchyma - the largest was $32 \mathrm{~mm}$ in segment $V$ and $17 \mathrm{~mm}$ in segment II. Histological examination showed a solid-pattern malignant neoplasm constituted by cells with a brownish pigment (C) and melan-A expression in the immunohistochemical study (D). 
